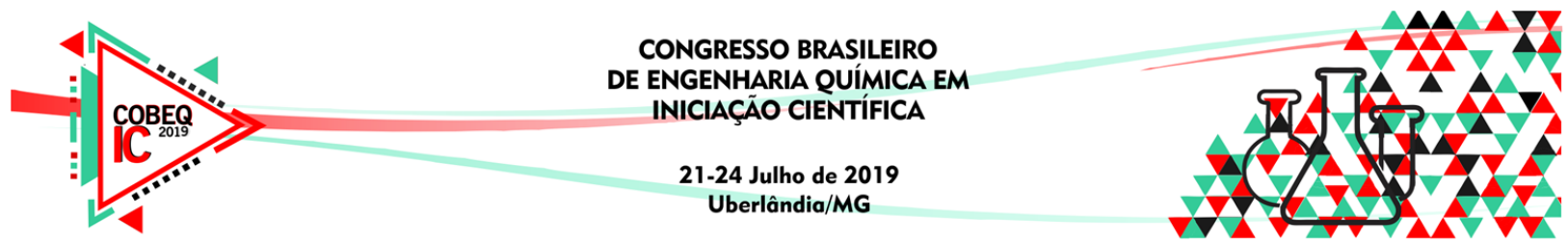

\title{
ESTUDO DE DIFERENTES PRÉ-TRATAMENTOS PARA OBTENÇÃO DE MICROFIBRAS EM CASCAS DE CAFÉ
}

\author{
M. G. SOARES ${ }^{1}$, C. G. SILVA ${ }^{1}$, V. C. R. SCHMIDT ${ }^{1}$ \\ ${ }^{1}$ Universidade Federal de Uberlândia, Faculdade de Engenharia Química \\ E-mail para contato: vivian@feq.ufu.br
}

\begin{abstract}
RESUMO - O uso de pré-tratamentos para modificação estrutural da celulose têm sido investigados a fim de aumentar a afinidade das fibras com matriz de amido promovendo melhorias das propriedades mecânicas. Nesse contexto, o objetivo é avaliar a influência de diferentes pré-tratamentos na composição química de cascas de café. As cascas de café foram higienizadas para retirar sujidades superficiais e evitar o aparecimento de insetos e peneiradas em malha 35 mesh Tyler para garantir a padronização das partículas e em seguida submetidas a três diferentes pré-tratamentos tratamentos com uso de $\mathrm{NaOH}$ : autoclave, micro-ondas e agitação. $\mathrm{O}$ estudo do efeito na composição química dessas cascas pré-tratadas com e sem a etapa de branqueamento foi investigada. Os resultados mostraram que as cascas moídas tratadas em autoclave (CMAC) foram as que obtiveram maior extração de lignina e aumento no teor de celulose, quando branqueadas. O prétratamento com autoclave e branqueamento melhoram a abertura das fibras, facilitando a hidrólise de ácidos orgânicos.
\end{abstract}

\section{INTRODUÇÃO}

Os plásticos formam montanhas em lixões e ilhas em rios e lagos que estão espalhadas pelo mundo. Estes derivados do petróleo, o plástico nunca se degrada por completo na natureza. $\mathrm{O}$ material apenas se quebra em pedaços cada vez menores, em um processo de decomposição que pode levar centenas de anos (Rosa et al., 2010).

A procura por materiais de fontes renováveis é o foco da evolução tecnológica nos últimos anos. Tanto em linhas de pesquisas com experimentos laboratoriais como em escala industrial na elaboração de novos produtos com tecnologia sustentável oriunda de fontes renováveis (De Lima, 2016).

O uso de fibras naturais como agente de reforço no setor plástico tem se revelado bastante promissor devido à sua larga abundância, caráter renovável e sustentabilidade ao meio ambiente além de proporcionarem materiais de alto desempenho mecânico (Teodoro et al., 2011). As vantagens da utilização de fibras naturais, principalmente lignocelulósicas em polímeros são a baixa densidade, a baixa abrasividade, a possibilidade de incorporação de altos teores resultando em elevada rigidez, a manutenção da recyclability (reciclabilidade), a biodegradabilidade e a grande variedade de cargas de reforço existentes (Machado et al., 2010). 


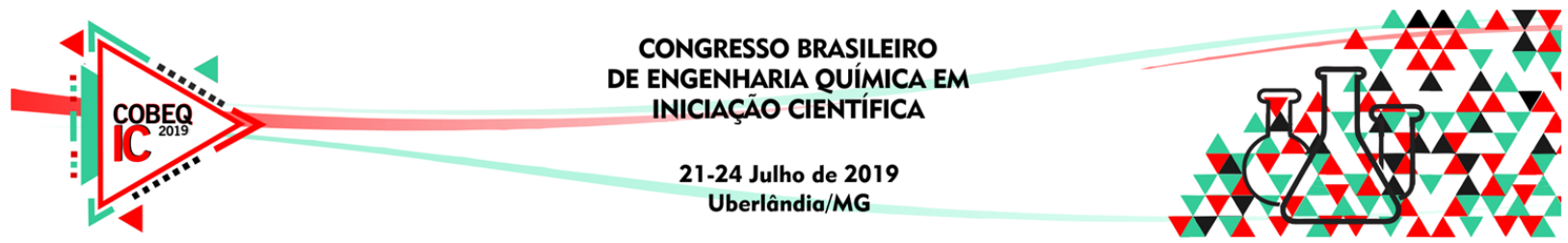

Assim, o objetivo foi aplicar diferentes pré-tratamentos (autoclave e micro-ondas, utilizando temperatura e solução de hidróxido de sódio) em cascas de café para estudo na modificação da composição química, especialmente a retirada de lignina e o aumento de celulose, e a eficiência dos mesmos na melhoria da permeação dos ácidos nas regiões amorfas no processo de hidrólise.

\section{MATERIAIS E MÉTODOS}

Os materiais utilizados na etapa de pré-tratamento foram hidróxido de sódio P.A (Êxodo Científica), ácido acético P.A glacial (Vetec), clorito de sódio 80\% (Sigma-Aldrich). A casca de café utilizada neste projeto foi gentilmente cedida pela fazenda Santa Anésia localizada na cidade de Cássia dos Coqueiros - SP. Resíduos da variedade Arábica constituídos pela casca de café, pergaminho e grãos de café que provém do processo de tratamento a seco do grão.

- Cascas moídas (CM): Para retirar sujidades superficiais e evitar o aparecimento de insetos os resíduos foram higienizados com água e secas em estufa micro processada com circulação forçada (QUIMIS) a $80^{\circ} \mathrm{C}$, por 12 horas. Após a secagem, foram trituradas em moinho de facas tipo Willey Star ft 50 (FORTINOX, BRASIL) e peneiradas em malha 35 mesh Tyler para garantir a padronização das partículas.

- Pré-tratamento em Agitação (PTAG): este método é comumente utilizado na literatura, as $\mathrm{CM}$ foram submetidas ao tratamento com solução de hidróxido de sódio de $2 \%(\mathrm{p} / \mathrm{p})$, por $4 \mathrm{~h}$ a $100^{\circ} \mathrm{C}$ sob agitação mecânica forte e intensa, em seguida lavadas com água destilada até sua neutralidade. As PTAG foram secas a $40^{\circ} \mathrm{C}$ durante $24 \mathrm{~h}$ em estufa de circulação de ar

- Pré-tratamento em Autoclave (PTAC): utilizou-se erlenmeyer de $500 \mathrm{ml}$, onde foi colocado a $\mathrm{CM}$ na proporção de $1: 20(\mathrm{~m} / \mathrm{v})$ de solução $\mathrm{NaOH} 5 \%(\mathrm{~m} / \mathrm{v})$, por 30 minutos, a $121^{\circ} \mathrm{C}$ e 2 atm, este procedimento foi feito apenas uma vez. Após o tratamento na autoclave, a PTAC foi lavada com água comum até o $\mathrm{pH}$ se ajustar próximo a 7,0, sendo em seguida lavada duas vezes com água destilada. Uma parte da umidade foi retirada com filtração à vácuo. Depois a amostra foi seca durante $24 \mathrm{~h}$ em estufa de recirculação de ar a $40^{\circ} \mathrm{C}$.

- Pré-tratamento em Micro-ondas (PTMO): colocou-se $10 \mathrm{~g}$ de casca em $100 \mathrm{ml}$ de solução de hidróxido de sódio a $5 \%$ em um erlenmeyer de $500 \mathrm{ml}$ sendo levado às micro-ondas por 5 minutos na potência máxima. Este procedimento foi repetido por duas vezes. Em seguida foi adicionado água fria e a PTMO foi filtrada e lavada com água da torneira até que o $\mathrm{pH}$ do eluído fosse de aproximadamente $7 \mathrm{e}$, posteriormente seco a $40^{\circ} \mathrm{C}$ durante $24 \mathrm{~h}$ em uma estufa com circulação de ar.

- Branqueamento: as fibras foram branqueadas com uma solução composta de partes iguais (v:v) de tampão acetato ( $27 \mathrm{~g}$ de hidróxido de sódio e $75 \mathrm{ml}$ de ácido acético glacial, diluídos a $1 \mathrm{~L}$ de água destilada) e clorito de sódio aquoso ( $\mathrm{NaClO} 2$ em água a 1,7\% $\mathrm{m} / \mathrm{m}$ ). $\mathrm{O}$ branqueamento foi realizado a $80{ }^{\circ} \mathrm{C}$ durante 4 horas. As PTAG, PTAC, PTMO branqueadas foram filtradas, lavadas com água da torneira até que o $\mathrm{pH}$ chegasse a aproximadamente 7 . Posteriormente secas a $40{ }^{\circ} \mathrm{C}$ durante 24 horas em uma estufa com circulação de ar. 


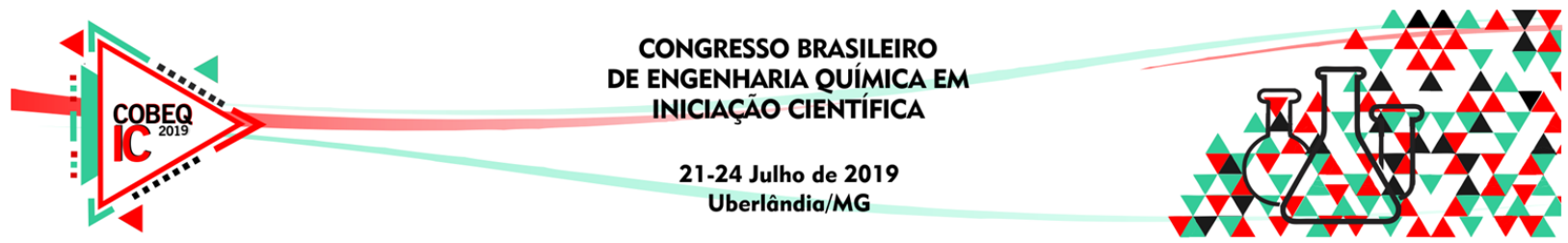

\subsection{Caracterização química}

A caracterização foi realizada para as cascas CMAG, CMAC e CMMO, com e sem branqueamento. A determinação do teor de lignina Klason insolúvel foi realizada seguindo a norma TAPPI T13M-54 modificada e a lignina solúvel foi quantificada por meio da espectroscopia na região do ultravioleta de acordo com a norma TAPPI T13M-54 modificada. Os teores de holocelulose foram quantificados pelo método do clorito ácido, a $\alpha$-celulose por extração alcalina e a hemicelulose foi calculada indiretamente pela diferença entre os teores de holocelulose e $\alpha$-celulose.

\section{RESULTADOS E DISCUSSÃO}

Confirmando a análise de observação visual das fibras, na Tabela 1 estão os valores encontrados para a composição química CM, PTAC, PTMO, PTAG sem branqueamento. Observa-se que as amostra dos pré-tratamentos sem branqueamento tiveram sua composição alterada, contudo não é o resultado esperado. Ao analisar os percentuais de hemicelulose e lignina ocorre pouca diferença nos valores, não indicando liberação de celulose, ficando bastante material amorfo na estrutura. Em comparação, os resultados das amostras com o branqueamento, tiveram a lignina extraída, com resultados próximos a zero. Estes resultados demonstram que PTAC e PTMO junto com o branqueamento em uma única etapa aproximamse de valores obtidos na literatura.

Tabela 1 - Composição química das fibras de cascas de café sem e com branqueamento.

\begin{tabular}{|c|c|c|c|c|c|}
\hline & & CM & PTAG & PTAC & РТМO \\
\hline & Lig. insolúvel & $30,78 \pm 0,441$ & $37,90 \pm 0,450$ & $41,06 \pm 5,115$ & $22,14 \pm 0,732$ \\
\hline Fibras não & Lig. solúvel & $0,032 \pm 0,367$ & $0,040 \pm 0,001$ & $0,014 \pm 0,002$ & $0,008 \pm 0,001$ \\
\hline \multirow[t]{5}{*}{ Branqueadas } & Holocelulose & $34,60 \pm 2,958$ & $61,90 \pm 1,040$ & $65,31 \pm 0,524$ & $69,66 \pm 0,449$ \\
\hline & $\alpha$-celulose & $17,40 \pm 1,718$ & $33,90 \pm 1,060$ & $45,95 \pm 0,319$ & $38,19 \pm 0,094$ \\
\hline & Hemicelulose & $12,41 \pm 2,158$ & $28,90 \pm 1,020$ & $19,53 \pm 0,344$ & $31,32 \pm 0,628$ \\
\hline & & CM & PTAG & PTAC & РТМO \\
\hline & Lig. insolúvel & $30,78 \pm 0,441$ & $35,90 \pm 0,450$ & $9,55 \pm 3,431$ & $5,670 \pm 1,130$ \\
\hline Fibras & Lig. solúvel & $0,032 \pm 0,367$ & $0,030 \pm 0,001$ & $0,007 \pm 0,000$ & $0,022 \pm 0,002$ \\
\hline \multirow[t]{3}{*}{ Branqueadas } & Holocelulose & $34,60 \pm 2,958$ & $58,90 \pm 1,040$ & $87,55 \pm 1,235$ & $79,46 \pm 1,443$ \\
\hline & $\alpha$-celulose & $17,40 \pm 1,718$ & $34,20 \pm 1,030$ & $61,01 \pm 0,629$ & $47,37 \pm 0,336$ \\
\hline & Hemicelulose & $12,41 \pm 2,158$ & $24,70 \pm 1,020$ & $26,55 \pm 0,734$ & $32,05 \pm 1,117$ \\
\hline
\end{tabular}




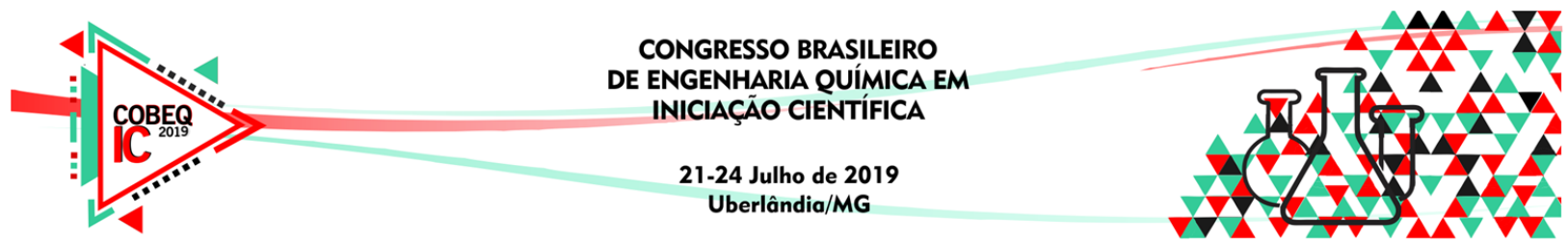

Fonte: Autoria própria.

Sendo que após o branqueamento, o teor de celulose aumenta significativamente, o teor de hemicelulose reduziu ligeiramente e o de lignina reduz para cerca de dois terços do original. Levando em conta que o branqueamento foi feita para remover os constituintes não celulósicos e principalmente a lignina, que age como um aglutinante natural dificultando o ataque ácido, o processo de branqueamento atingiu o seu objetivo, uma vez que a composição da casca branqueada é adequada para a extração de fibras por hidrólise ácida.

Observa-se um crescente aumento no teor de celulose após cada pré-tratamento, assim como a diminuição das concentrações de hemicelulose e lignina. O tratamento com $\mathrm{NaOH} 5 \% \mathrm{~m} / \mathrm{v}$ foi responsável pela remoção da maior parte de lignina, cujo teor caiu de $28,0 \%$ para apenas $13,7 \%$ após esse tratamento. Igual ao que foi reportado por Nascimento e Rezende (2016) no estudo com folhas de capim elefante. Observou-se que para a porcentagem de hemicelulose, houve uma redução de $24,8 \%$ para $16,8 \%$. O tratamento com peróxido alcalino apresentou também um efeito significativo sobre a remoção de hemicelulose e de lignina das amostras de folhas de capim. Esse efeito é coerente com o branqueamento que é responsável por remover os componentes mais recalcitrantes da parede celular, que permaneceram aos pré-tratamentos estudados (micro-ondas e autoclave).

\section{CONCLUSÃO}

A partir dos resultados obtidos, pode-se concluir que os pré-tratamentos foram eficientes na modificação estrutural das fibras. $\mathrm{O}$ tratamento PTAC foi o que apresentou melhores resultados, apresentando baixos valores de lignina e um aumento no teor de celulose.

\section{AGRADECIMENTOS}

Os autores gostariam de agradecer a FAU-UFU, ao CNPq, à CAPES, à FAPEMIG (Brasil) e à Universidade Federal de Uberlândia pelo apoio durante todo o trabalho.

\section{REFERENCIAS}

BENINI, K.C.C.C. Desenvolvimento e caracterização de compósitos poliméricos reforçados com fibras lignocelulósicas: HIPS/fibra da casca do coco verde e bagaço de cana de açúcar, 2011. 125f. Dissertação (Mestrado) -Engenharia Mecânica - Universidade Estadual Paulista, Faculdade de Engenharia de Guaratinguetá, Guaratinguetá, 2011.

FORTUNATI E., LUZI F., PUGLIA D., PETRUCCI R., KENNY J.M., TORRE L. Processing of PLA nanocomposites with cellulose nanocrystals extracted from Posidonia oceanica waste: innovative reuse of coastal plant. Industrial Crops and Products, Inglaterra, v. 67, p. 439-447, maio 2015.

ROSA, M. F.; MEDEIROS, E.S.; MALMONGE, J.A.; GREGORSKI, K.S.; WOOD, D.F.; MATTOSO, L.H.C.; GLENN, G.; ORTS, W.J.; IMAM, S.H. Cellulose nanowhiskers 


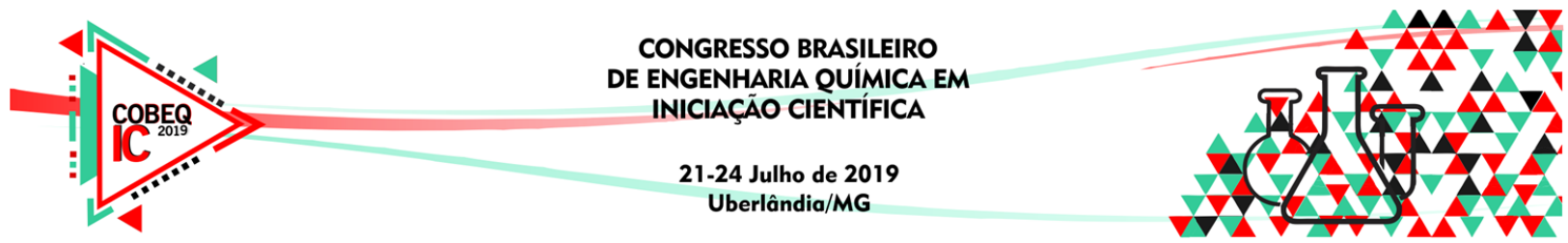

from coconut husk fibers: Effect of preparation conditions on their thermal and morphological behavior. Carbohydrate Polymers, 2010.

SAELEE, K.; YINGKAMHAENG, N.; NIMCHUA, T.; SUKYAI, P. An environmentally friendly xylanase-assisted pretreatment for cellulose nanofibrils isolation from sugarcane bagasse by high-pressure homogenization. Industrial Crops and Products, Inglaterra, v. 82, p. 149-160, 2016.

SIRÓ, I.; PLACKETT, D. Microfibrillated cellulose and new nanocomposite materials: a review. Cellulose, França, (2010) 17:459-494

TEODORO, K. B. R. Whiskers de fibra de sisal obtidos sob diferentes condições de hidrólise ácida: efeito do tempo e da temperatura de extração. Polímeros, [s.1.], v. 21, n. 4, p.280285, 23 set. 2011. FapUNIFESP (Scielo). 